\title{
Comment
}

\section{Características Qualitativas da Pesquisa Científica: Uma visão para pesquisas qualitativas e quantitativas}

\author{
Leilson Vanderson Barbosa da Silva ${ }^{1}$; Marciel José do Monte $^{2}$; Nadielli Maria dos Santos Galvão ${ }^{3}$;osé Jonas Alves Correia
}

Resumo: A pesquisa se constitui em uma importante atividade no âmbito das instituições de ensino superior, com o propósito de desenvolver e/ou aperfeiçoar técnicas e estratégias de trabalho e ação nos diversos ramos de atividade, além de constituir-se como algo fundamental para o avanço do conhecimento e construção de soluções para os problemas sociais. Este comment discute os conceitos de validade, confiabilidade e generalização, usuais às pesquisas quantitativas, como possibilidade também nas pesquisas de cunho qualitativo.

Palavras-chave: Pesquisa qualitativa, validade, confiabilidade, generalização.

\section{Qualitative Characteristics of Scientific Research: A vision for qualitative and quantitative research}

\begin{abstract}
The research is an important activity in higher education institutions, with the purpose of developing and / or improving techniques and strategies of work and action in the various branches of activity, besides being fundamental for the Advancement of knowledge and construction of solutions to social problems. This comment discusses the concepts of validity, reliability and generalization, common to quantitative research, as a possibility also in qualitative research.
\end{abstract}

Keywords: Qualitative research, validity, reliability, generalization.

\section{Considerações iniciais}

A pesquisa se constitui em uma importante atividade no âmbito das instituições de ensino superior, com o propósito de desenvolver e/ou aperfeiçoar técnicas e estratégias de trabalho e ação nos diversos ramos de atividade, além de constituir-se como algo fundamental para o avanço do conhecimento e construção de soluções para os problemas sociais. (OLIVEIRA e MARTINS, 2014).

\footnotetext{
${ }^{1}$ Professor da Faculdade Nova Roma (FGV); Professor da FAJOLCA - Faculdade do Ipojuca; Mestre em Ciências Contábeis (UFPE); Bacharel em Ciências Contábeis (UFPE). E-mail: leilsonvanderson15@gmail.com

${ }^{2}$ Mestrando no Programa de Pós-graduação em Educação Matemática e Tecnológica da UFPE (EDUMATEC); MBA em Administração Pública pela Faculdade Estácio do Recife. E-mail: marciel.monte@gmail.com

${ }^{3}$ Professora Assistente da Universidade Federal de Sergipe (UFS); Mestra em Ciências Contábeis (UFPE); Endereço: Campus Universitário Prof. Alberto Carvalho, Av. Vereador Olímpio Grande, s/n, bloco departamental - $1^{\circ}$ Andar, Itabaiana - Sergipe - Brasil CEP: 49.500-000. Email: profa.nadielligalvao@gmail.com

${ }^{4}$ Mestrando em Ciências Contábeis (UFPE); Especialista em Prática Docente no Ensino Superior (FIP) e Gestão Empresarial (FVJ); Bacharel em Ciências Contábeis (FJN) e Economia (URCA). E-mail: jhonnasallves@ hotmail.com
} 
No cenário brasileiro, tem-se a CAPES (Coordenação de Aperfeiçoamento de Pessoal de Nível Superior), como órgão financiador e incentivador das pesquisas acadêmicas, auxiliando financeiramente os pesquisadores que tenham vínculo com algum programa de pósgraduação stricto sensu, que são normalmente ofertados por universidades públicas.

Se por um lado temos este órgão incentivando os pesquisadores, por outro, temos um fator limitador das pesquisas, uma vez que o alcance de metas de publicações estabelecidas pela CAPES pode prejudicar a qualidade das pesquisas acadêmicas brasileiras, colocando em risco o valor da pesquisa científica, cuja determinação se dá geralmente pela validade, confiabilidade e generalização.

Esses conceitos de validade, confiabilidade e generalização são mais usuais às pesquisas quantitativas, no entanto, não deixam de fazer parte também das pesquisas de cunho qualitativo, podendo, inclusive, serem adotadas novas "denominações" a eles, entendendo que as naturezas das pesquisas são distintas e filosoficamente diferentes, além de serem critérios que servem de avaliação da cientificidade de uma pesquisa acadêmica. De acordo com André (2001) as inquietações acerca dos critérios que avaliam a cientificidade de uma produção surgiram a partir do século XIX, quando cientistas sociais passaram a questionar o modelo tradicional de pesquisa que se baseava em critérios clássicos de cientificidade como validade, fidedignidade e generalização, por entenderem que estes não davam conta das novas abordagens de pesquisa, sobretudo dos estudos qualitativos que buscavam compreender os fenômenos humanos e sociais.

Diante do exposto, este ensaio visa discorrer sobre os significados de confiabilidade, validade e generalização, entendo que eles podem variar dentro das posições filosóficas e teóricas dos pesquisadores.

\section{Validade}

Para Martins (2006) toda medida deve reunir dois requisitos essenciais: confiabilidade e validade. Sendo as medias confiáveis aquelas que podem ser replicadas e consistentes, ou 
seja, geram sempre os mesmos resultados. Já as medidas válidas, são aquelas representações precisas das características que se pretende medir.

Brinberg \& McGrath (1985) preconizam que a validade não é uma commodity que pode ser comprada com técnicas, mas um estado ideal, ou seja, um conceito a ser perseguido pelos pesquisadores. Eles dizem ainda que, na ciência social moderna, o termo validade tem relação com uma série de significados: convergência, correspondência, diferenciação, equivalência, generalidade, repetibilidade, entre outros.

Em pesquisa científica, a validade assume concepções mais complexas. A elaboração original do conceito vem de métodos quantitativos nos quais a validade é a extensão em que uma medida representa corretamente o conceito do estudo, ou seja, o grau em que a medida está livre de qualquer erro. A validade seria referente à semelhança entre o conceito e suas medidas, ao grau em que uma medida representa precisamente o que se espera. A garantia da validade começaria com a compreensão direta do que deve ser medido, sendo, portanto, uma questão prioritariamente de formulação da pesquisa (HAIR Jr. et al., 2009). Em outras palavras, uma pesquisa só terá validade se ela conseguir responder aquilo que se propôs a estudar.

Na visão de Martins (2004) nas pesquisas quantitativas, como o pano de fundo é basicamente a filosofia positivista, a validade é um atributo que tem uma relação direta com a objetividade, com a possibilidade de repetição do experimento, com o fato de a pesquisa estar aberta à verificação por outras pessoas e com a capacidade de generalização. Sendo assim, para que uma pesquisa de natureza quantitativa seja considerada válida, outro pesquisador tem que desenvolvê-la e conseguir chegar ao mesmo resultado que fora encontrado. Nesse contexto, a ciência tem caráter explicativo e é vista de maneira mais objetiva.

Em complemento ao que fora apresentado, Golafshani (2003) diz que os critérios tradicionalmente adotados para verificação da existência de validade em pesquisas têm suas raízes no positivismo; entendendo o positivismo como definido pela sistematização da validade.

No entanto, no que se refere às pesquisas de cunho qualitativo, segundo Ollaik e Ziller (2012) a concepção de validade assume formas distintas, pois a discussão sobre escalas de medição não se aplica a métodos qualitativos, sendo necessária a compreensão da validade em outra perspectiva. Para além de questões de formulação, naquilo que pode ser compreendida como validade prévia, a validade vai buscar indicar o que constitui uma pesquisa bem feita, confiável, sendo esta merecedora de ser tornada pública a fim de contribuir para o 
conhecimento, ou - conforme a definição apresentada inicialmente para o termo válido - que tem valor, eficaz.

\section{Confiabilidade}

A confiabilidade de uma pesquisa nada mais é do que a confiança que a mesma traz. Os instrumentos de medição do mundo físico, em geral, oferecem um grau de confiança bastante elevado, devido à relativa estabilidade dos fenômenos observados. No entanto, nem sempre o mesmo acontece em relação às medidas de variáveis do universo social, onde a instabilidade dos fenômenos e fatos observados dificulta a própria construção de instrumentos de aferição, uma vez que as contínuas modificações do ambiente tornam mais difíceis à determinação da constância das medidas, isto é, normalmente dificultam um elevado grau de confiabilidade. (MARTINS, 2006)

Na visão de Mello, Leão e Paiva Jr (2011) entende-se confiabilidade como a consistência com que um procedimento de pesquisa irá avaliar um fenômeno da mesma maneira em diferentes tentativas. Contudo, Flick (2008) assegura que a pesquisa qualitativa tem seus critérios próprios de rigor científico que asseguram a legitimidade dos dados gerados em sua utilização.

Por exemplo, fazendo uma analogia, quando se diz que alguma pessoa é confiável, podese afirmar que o que ela diz hoje numa conversa, ou seja, as idéias que ela expõe, serão as mesmas que serão expostas em conversas futuras. Ou seja, essa pessoa é consistente e fidedigna.

De acordo com Selltiz (1987 apud MARTINS; 2006), uma medida confiável produzirá os mesmos resultados em sucessivas aplicações sobre o mesmo objeto ou sujeito.

Uma das maneiras de testar a confiabilidade num estudo quantitativo é usando o coeficiente Alpha de Cronbach, onde ele vai carecer de um instrumento de medição, cuja medida se dará, por exemplo, entre 0 e $100 \%$, assumindo que quando ele for maior que $70 \%$ existirá confiabilidade nas medidas.

Na pesquisa qualitativa, tende a ser observada nos seguintes aspectos: confiabilidade quixotesca, que se refere às circunstâncias em que um único método de observação mantém uma medida contínua; confiabilidade diacrônica, que se refere à estabilidade de uma observação 
através do tempo; e confiabilidade sincrônica, que se refere à similaridade de diferentes observações dentro de um mesmo período de tempo (KIRK; MILLER, 1986 apud JÚNIOR, LEÃO E MELO; 2011).

\section{Generalização}

A busca pela precisão numérica capaz de ser validada, confirmada e replicada representa a principal forma de construção de conhecimento em algumas áreas das ciências sociais. Os trabalhos que seguem a pesquisa quantitativa ainda são vistos por alguns pesquisadores como estudos realizados com maior rigor e neutralidade. A pesquisa qualitativa, embora tenha ampliado seu espaço e ganhado destaque, ainda é bastante questionada por alguns pesquisadores, que dizem que esta não possui o mesmo rigor de coleta e análise de dados da pesquisa quantitativa, bem como a força da generalização dos resultados encontrados. (OLIVEIRA e PICCININI, 2009)

Entrando em outra visão filosófica de pesquisa, Valles (1997) afirma que a generalização dos resultados buscada e considerada como critério de qualidade dos trabalhos clássicos, ou seja, os quantitativos de cunho positivista, devem ser considerados como equivalente à noção de transferibilidade adotada como critério de boa qualidade nas investigações qualitativas.

Para ela, transferibilidade deve-se entender não a reprodução dos resultados encontrados (generalização) sob as mesmas condições mantidas em estudos anteriores, mas, a possibilidade de utilização dos procedimentos e resultados encontrados em situações semelhantes, respeitados as peculiaridades dos novos contextos.

Nesse sentido, Mayring (2002) explana alguns conceitos de generalização para pesquisas com abordagem qualitativa. O primeiro conceito é o da generalização argumentativa. Onde ele aborda que à medida que os achados na pesquisa qualitativa se apóiem em estudo de caso, estes dependerão de uma argumentação realizada de maneira explícita de modo a apontar quais generalizações seria factível àquelas circunstâncias que envolvem aquele objeto de pesquisa em específico, o que seria diferente de uma pesquisa quantitativa, tendo em vista que 
apenas uma amostra representativa já traria segurança à possibilidade de generalizar os resultados.

Em complemento ao que fora apresentado, Günther (2006) afirma que se relaciona a isto a ênfase no processo indutivo, partindo de elementos individuais para chegar a hipóteses e generalizações. Entretanto, este processo deve seguir regras, que não são uniformes, mas específicas a cada circunstância. Desta maneira, é de suma importância que as regras sejam explicitadas para permitir uma eventual generalização. Finalmente, Mayring não exclui a quantificação, mas enfatiza que a função importante da abordagem qualitativa é a de permitir uma quantificação com propósito. Desta maneira, poder-se-ia chegar a generalizações mais consubstanciadas.

\section{Considerações Finais}

O presente ensaio buscou discutir alguns elementos inerentes à boa qualidade de uma pesquisa científica, dentro de abordagens filosóficas do pesquisador. Foi discutido sobre confiabilidade, validade e generalização associadas às pesquisas qualitativas e quantitativas.

No que se refere à validade das pesquisas, Ollaik e Ziller (2012) afirmam que concepção de validade assume formas distintas, uma vez que a discussão sobre escalas de medição não se aplica a métodos qualitativos, não deixando esses estudos de serem válidos, uma vez que eles detêm um rigor científico forte para fins de publicação.

Já em relação à confiabilidade das pesquisas, foi visto que em estudos quantitativos, se consegue atingi-la de forma mais objetiva, através de testes de verificação das variáveis dos estudos, no entanto, no que diz respeito às pesquisas de abordagem qualitativa, está também está presente só que de diferentes maneiras.

E no que se refere à generalização, vimos que esse termo é mais adotado em estudos quantitativos, no entanto, para estudo qualitativos, Valles (1997) diz que a transferibilidade têm equiparação à generalidade, deixando assim esses estudos no mesmo patamar.

A partir do apresentado neste ensaio, pode-se entender que a validade, a confiabilidade e a generalização da pesquisa não devem ser alcançadas apenas pelos estudos de visão 
positivista, devendo ter o entendimento de que estas estão relacionadas também com pesquisas qualitativas, não havendo superioridade entre elas.

\section{Referências}

ANDRÉ, M. Pesquisa em educação: buscando rigor e qualidade. Caderno de pesquisa. n. 113 p. 51-64, jul. 2001 Disponível em: 〈http://www.scielo.br/pdf/\%0D/cp/n113/a03n113.pdf>.

BRINBERG, D., \& McGrath, J. E.. Validity and the research process. Third printing, 1989. Sage Publications, Newbury Park, 1985, Califórnia.

FLICK, U. Uma introdução à pesquisa qualitativa. 3. ed. Porto Alegre: Bookman, 2008. GOLAFSHANI, Nahid. Understanding reliability and validity in qualitative research. The Qualitative Report, v. 8, n. 4, p. 597-607, dec. 2003.

GÜNTHER, Hartmut. Pesquisa Qualitativa versus Pesquisa Quantitativa: Esta é a questão?. Revista de Psicologia: Teoria e Pesquisa da UNB. Mai-Ago 2006, Vol. 22 n. 2, pp. 201-210.

HAIR Jr., Joseph F. et al. Análise multivariada de dados. 6. ed. Porto Alegre: Bookman, 2009.

KIRK, J.; MILLER, M. L. Reliability and validity in qualitative research. Thousand Oaks: Sage Publications, 1986.

MARTINS, Heloísa Helena T. de Souza. Metodologia qualitativa de pesquisa. Revista USP de Educação e Pesquisa, São Paulo, v. 30, n. 2, p. 289- 300, maio/ago. 2004.

MAYRING, Ph. (2002). Einführung in die qualitative Sozialforschung [Introdução à pesquisa social qualitativa]. ( $5^{\mathrm{a}}$ ed.). Weinheim: Beltz.

OLIVEIRA, Sidney Rocha de; PICCINICI, Valmira Carolina. Validade e reflexividade na pesquisa qualitativa. CADERNOS EBAPE. BR, v. 7, n 1, artigo 6, Rio de Janeiro, Mar. 2009

OLLAIK, Leila G.; ZILLER, Henrique M. Concepções de Validade em Pesquisas Qualitativas. Revista USP de Educação e Pesquisa, São Paulo, v.38, n.1, 229-241, 2012.

PAIVA JR, F. G.; LEÃO, A. L. M. S.; MELLO, S. C. B. Validade e Confiabilidade na Pesquisa Qualitativa em Administração. Revista de Ciências da Administração • v. 13, n. 31, p. 190-209, set/dez 2011.

KIDDER, Louise H. Métodos de pesquisa nas relações sociais. São Paulo: EPU, 1987. 
VALLES, M.S. (1997). Técnicas cualiltativas de investigacion social: Reflexion metodológica y práctica profesional Madri

\section{Como citar este artigo (Formato ABNT):}

SILVA, Leilson V. B.; MONTE, Marciel J.; GALVÃO, Nasielli M. S. CORREIA, José Jonas A. Características Qualitativas da Pesquisa Científica: Uma visão para pesquisas qualitativas e quantitativas.. Id on Line Revista Multidisciplinar e de Psicologia, Maio de 2017, vol.11, n.35, p.607-614. ISSN: 1981-1179.

Recebido: 22.11 .2016

Aceito: 31.05 .2017 